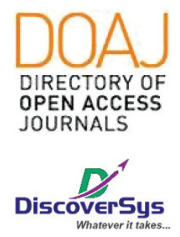

Published by DiscoverSys

\section{Management of denture foreign body in esophagus with cervical esophagotomy: case report}

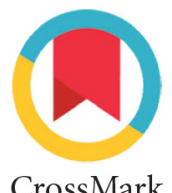

CrossMark

\author{
Kadek Yudi Fajar Mahendra ${ }^{1 *}$, Ketut Putu Yasa ${ }^{2}$
}

\begin{abstract}
Introduction: Impaction of dentures in the esophagus is a distressing experience for a patient and can lead to serious consequences, such as esophageal perforation. Patients with an impacted denture often present with a history of accidental swallowing, frequently during trauma, seizures, or sleep or in association with some degree of psychological dysfunction. The common signs and symptoms of an impacted denture are odynophagia, dysphagia, or simply pain and tenderness in the neck or chest.The preferred method of removal of esophageal foreign bodies is extraction with the flexible endoscope. Surgical removal is rarely indicated except in the event of perforation or other foreign body complications.In situations where this appears potentially hazardous, such as with impacted denture, open surgical extraction

by cervical oesophagotomy is promptly performed is a safe option. Cases Report: The successful removal of impacted denture in the esophagus in a patient is reported, with a review of the literature. A women23-year-old complained of dysphagia after swallowing his denture. Following unsuccessful attempts at removal via a rigid esophagoscope, open surgery was performed. Without further delay, the impacted denture was removed by cervical oesophagotomy, and the patient recovered uneventfully.

Conclusion: The successful removal of impacted denture by cervical oesophagotomy in the esophagus in a patient is reported. We conclude that cervical esophagotomy is a safe method for removing foreign bodies impacted in the cervical esophagus when they cannot be removed endoscopically.
\end{abstract}

Keywords: impacted denture, cervical oesophagotomy, management

Cite This Article: Mahendra, K.Y.F., Yasa, K.P. 2019. Management of denture foreign body in esophagus with cervical esophagotomy: case report. Intisari Sains Medis 10 (3): 597-599. D01: 10.15562/ism.v10i3.558

${ }^{1}$ General Surgery Resident, Department of General Surgery, Universitas Udayana-Sanglah General Hospital, Bali-Indonesia. ${ }^{2}$ Consultant of Thoracic and Cardio Vascular Surgeon, Department of Thoracic and Cardio Vascular Surgery, Universitas Udayana, Bali-Indonesia.
*Corresponding to: Kadek Yudi Fajar Mahendra, General Surgery Resident, Department of General Surgery, Universitas Udayana-Sanglah General Hospital, Bali-Indonesia; fajarnonik5858@yahoo.com

Received: 2019-06-30 Accepted: 2019-09-07 Published: 2019-12-01

\section{INTRODUCTION}

Ingestion of foreign bodies is common especially among the pediatric age group, whereas in adults occur more commonly among those with psychiatric disorders, or mental retardation, prisoners and alcoholics. Fortunately, most of them pass through the gastrointestinal tract harmlessly. However, $10-20 \%$ will require nonoperative intervention and only $1 \%$ or less surgery. ${ }^{1,2,4,5,8}$

Impaction of dentures in the esophagus is a distressing experience for a patient and can lead to serious consequences, such as esophageal perforation. Patients with an impacted denture often present with a history of accidental swallowing, frequently during trauma, seizures, or sleep or in association with some degree of psychological dysfunction. The common signs and symptoms of an impacted denture are odynophagia, dysphagia, or simply pain and tenderness in the neck or chest. ${ }^{2,4,5,8}$

\section{CASE REPORT}

23-year-old women swallowed his denture while drinking water 4 hours before admission.She complained of dysphagia, blood-stained sputum, and pain localized to lower part of his neck. Cervical radiographs antero-lateral (Figure 1) revealed a linear C-shaped opacity located anterior and left to the C7 vertebra, consistent with the wire clasp of a denture. An otolaryngologist examined under general anesthesia with rigid oesophagoscopy 8 hours after admission.

A large denture was noted $22 \mathrm{~cm}$ distal to the incisors. Superficial lacerations of esophagus were noted at the denture site. The wire of the denture could not be seen, suggesting it to be inferiorlypositioned. Multiple attempts were made to remove the denture with forceps through the rigid esophagoscope but the denture could not be dislodged.

The patient was referred to Thoracic and Cardio Vascular Surgeon for open surgical removal, 12 hours after admission. Under general anesthesia, a left transverse neck incision was made. The strap muscles of the neck were divided. The middle thyroid vein was ligated and through the space between thyroid gland and carotid sheath, the cervical and upper thoracic esophagus were identified. A cotton tape was placed to encircle the 

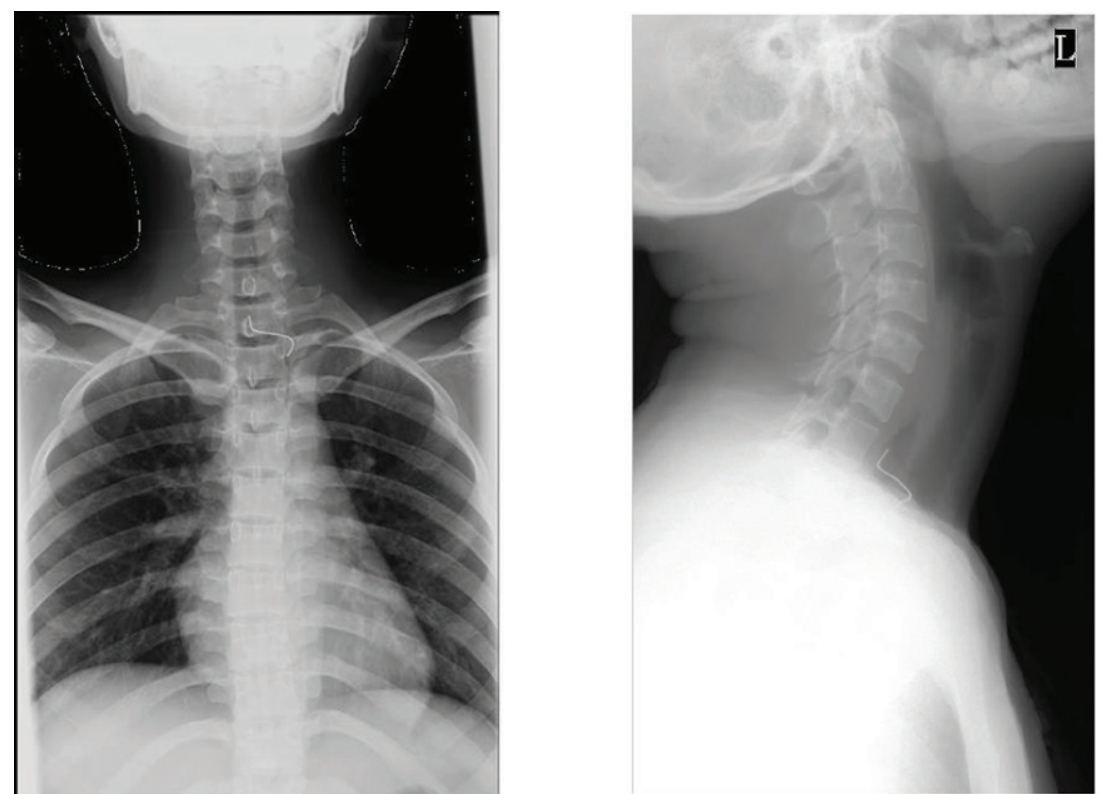

Figure 1. Anterolateral radiograph of the cervical spine shows the denture wire at $\mathrm{C} 7$ level.
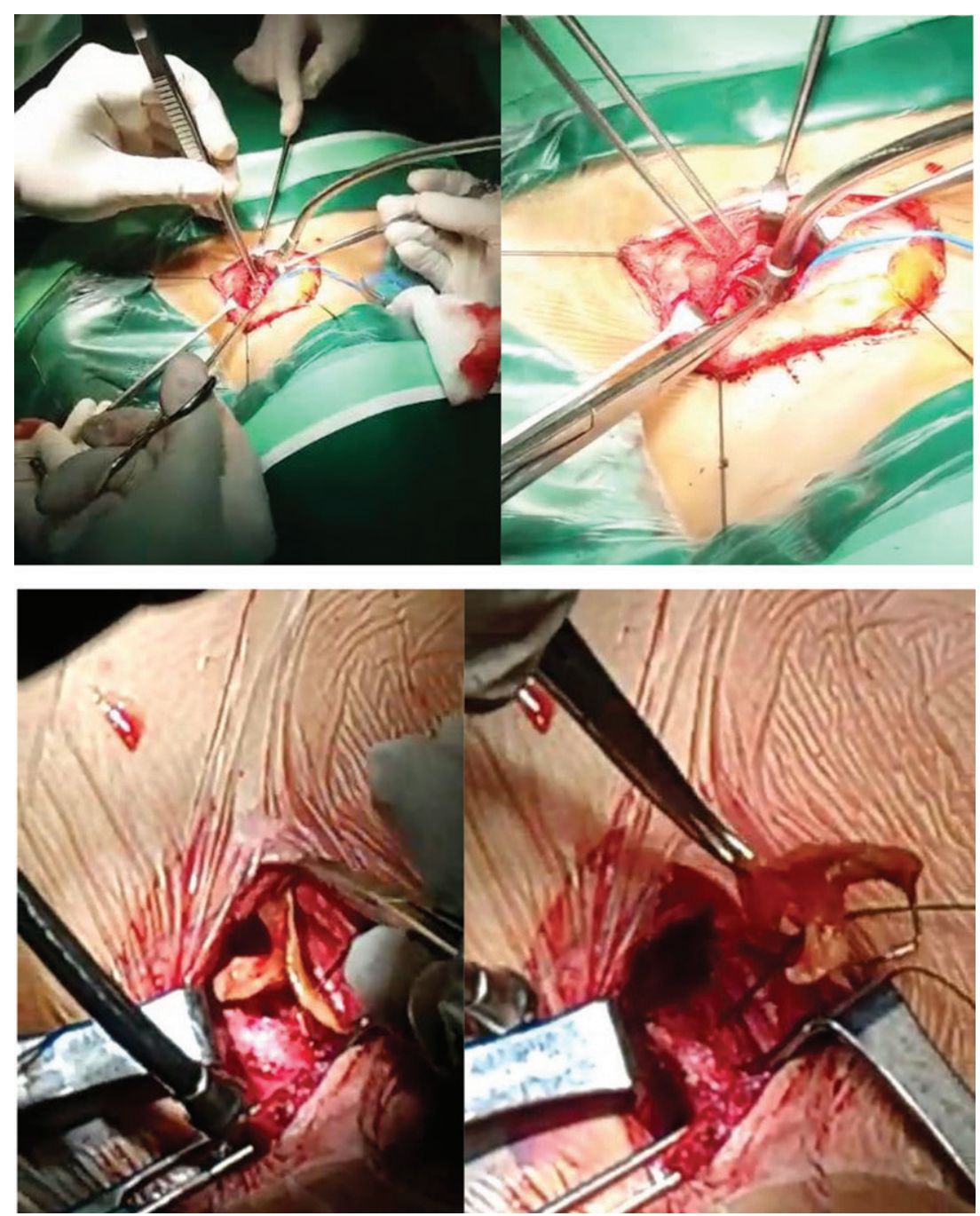

Figure 2. Operative photograph shows the denture being retrieved via oesophagostomy. esophagus taking care not to damage the recurrent laryngeal nerves. A transverse incision was made at the site of the impacted foreign body (Figure 2). A $3.5 \mathrm{~cm}$ long acrylic broken denture was found in the esophagus (Figure 3). Following manual removal of the impacted denture, the oesophagostomy was repaired with a single layer of interrupted 3-0 vicryl.

The patient recovered well in the postoperative period. She was kept nil-by-mouth for the first postoperative day, and nasogastric feeding was started on the second postoperative day. Intravenous ceftriaxone was given for a total for seven days. After 5 daysshe has recovered uneventfully and is taking a normal diet.

\section{DISCUSSION}

In Western literature, meat is the main foreign body ingested in adults, and coins are the most frequent object in children. Following foreign body ingestion, patients usually present with dysphagia (92\%) and tenderness of the neck (60\%). Other symptoms include: inability to swallow oral secretions, hypersalivation, retrosternal fullness, regurgitation of undigested food, and odynophagia. In children, stridor and dyspnoea may be encountered due to tracheal compression. ${ }^{1,2,4,5}$

Impacted foreign bodies in the esophagus can easily cause mucosal ulceration, inflammation or even infections and can also result in various fatal complications such as para- or retroesophageal abscess, mediastinitis, empyema, perforation or even aortoesophageal fistula. The latter is a rare and usually fatal cause of upper gastrointestinal hemorrhage. Prompt and effective bleeding control and left thoracotomy with primary suture of esophageal and aortic defect could be life-saving. $1,2,3,4,5,8$

The diagnosis is usually easily elicited if the patient can give a reliable history, as is the case with our patient. Radiological imaging can determine the exact site of radio-opaque impacted foreign body, as well as air entrapment if there is perforation. Dentures, however, are frequently made of acrylic resin which is radiolucent, though the radioopaque wire clasps of the denture can sometimes be seen, if present, as in this patient. Because of its large size, sharp edges, metal clasps, endoscopic extraction of dentures carries a high risk of oesophageal perforation. ${ }^{2,4,5}$ Successful endoscopic extraction needs considerable experience, good visualization during rigid oesophagoscopy, and the use of shears forceps. ${ }^{5,8,9}$ If a denture is found via rigid esophagoscopy to be deeply embedded in the wall of the esophagus, then esophagotomy is the best option for removing the dental prosthesis This surgery may be performed through a cervical 


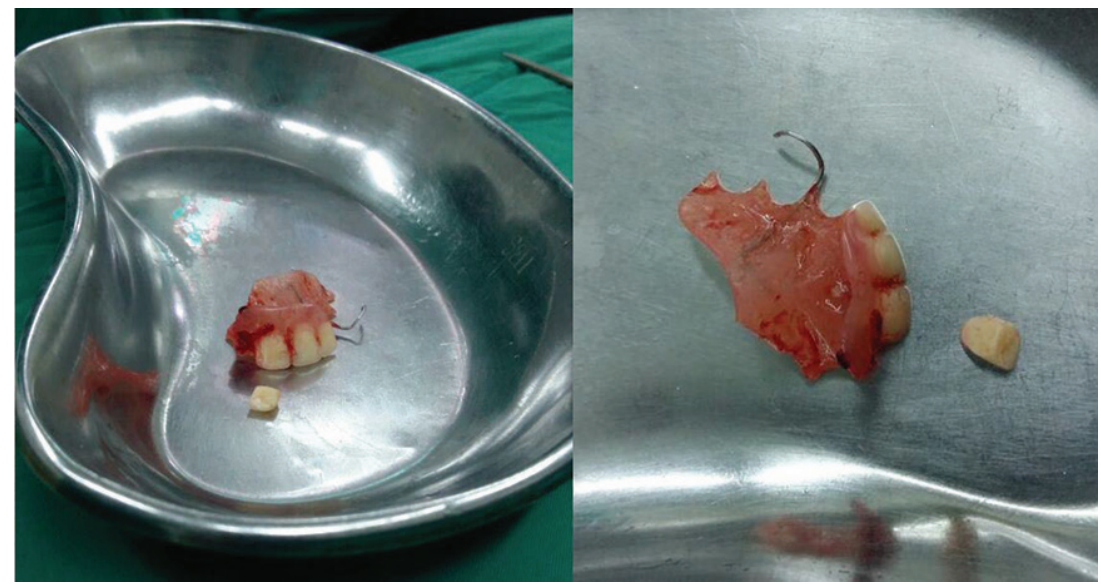

Figure 3. Denture Foreign Body

or thoracic approach, depending on the level of impaction. ${ }^{4,8,9,10}$ In our patient, the denture wire causing impaction could not be visualized and hence, there was no means of removing it endoscopically.

Most swallowed foreign bodies are impacted at the cervical and upper esophagus and can be removed by cervical oesophagostomy without thoracotomy. ${ }^{2,9,10}$ The experience of this present case illustrates that prompt management of an impacted denture in the esophagus leads to quick and uneventful recovery. We conclude that cervical esophagotomy is a safe procedure for the removal of foreign bodies impacted in the cervical esophagus that are not amenable to endoscopic removal.

\section{CONCLUSION}

The successful removal of impacted denture by cervical oesophagotomy in the esophagus in a patient is reported.The preferred method of removal of esophageal foreign bodies is extraction with the flexible endoscope. Surgical removal is rarely indicated except in the event of perforation or other foreign body complications.In situations where this appears potentially hazardous, such as with impacted denture, open surgical extraction by cervical oesophagotomy is promptly performed is a safe option.

\section{CONFLICT OF INTEREST}

The author declares there is no conflict of interest regarding publication of current report.

\section{ETHICAL ASPECT}

The patient has received signed informed consent for publication of their respective photograph in journal article.

\section{REFERENCES}

1. Yadav R, Mahajan G, MAthur RM. Denture Plate Foreign Body of Esofagus. International Journal of Thoracic Vascular Surgery. 2008;24:191-4.

2. Athanassiadi $\mathrm{K}$, et al. Management of esophageal foreign bodies: a retrospective review of 400 cases. European Journal of Cardio-thoracic Surgery. 2002;21:653-656.

3. Peters JH, Demeester T. Esofagus and Diaphragmatic Hernia in Schwartz's Principles of Surgery. 8th ed. New York: McGraw Hill; 2010. p. 836-40.

4. Zakariya IM, et al. Cervical esophagotomy for an impacted denture: A case report. Ear Nose Throat J. 2009;88(3):833-4.

5. Chua YKD, See JY, Ti TK. Oesophagealimpacted denture requiring open surgery. Singapore Med J. 2006;47(9):820-23.

6. Luigi Bonavina et al.Thoracoscopic removal of dental prosthesis impacted in the upper thoracic esophagus. World Journal of Emergency Surgery. 2014;9:5.

7. Rathore PK, Raj A, et al. Prolonged foreign body impaction in the oesophagus. Singapore Med J. 2006;50(2):e53

8. Nwaorgu OG, Onakoya PA, Sogebi OA, Kokong DD, Dosumu OO, et al. Esophageal Impacted Dentures. J Nation Med Assoc. 2004; 96:1350-3.

9. Miyazaki T, Hokaman N, Kubo N, Ishiguro T, Sakimoto T, et al. Management of Esophageal Foreign Bodies: Experience of 90 Cases. Esophagus. 2009;6:155-9.

10. Ekim H. Management of esophageal foreign bodies: A report on 26 patients and literature review. Eastern Journal of Medicine. 2010;15:21-5.

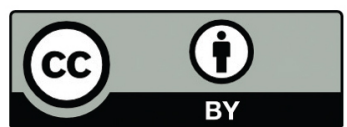

This work is licensed under a Creative Commons Attribution 